\title{
Cadmium and Copper
} Cross-Tolerance. $\mathrm{Cu}^{+}$Alleviates $\mathrm{Cd}^{2+}$ Toxicity, and Both Cations Target Heme and Chlorophyll Biosynthesis Pathway in Rubrivivax gelatinosus

\author{
Anne Soisig Steunou, Anne Durand, Marie-Line Bourbon, Marion Babot, Reem Tambosi, \\ Sylviane Liotenberg and Soufian Ouchane*
}

Université Paris-Saclay, CEA, CNRS, Institute for Integrative Biology of the Cell (I2BC), Gif-sur-Yvette, France

OPEN ACCESS

Edited by:

Davide Zannoni,

University of Bologna, Italy

Reviewed by:

Daniel Raimunda,

Medical Research Institute Mercedes and Martín Ferreyra (INIMEC),

Argentina

Manuel González-Guerrero,

Polytechnic University of Madrid,

Spain

*Correspondence:

Soufian Ouchane

soufian.ouchane@i2bc.paris-saclay.fr

Specialty section:

This article was submitted to Microbial Physiology and Metabolism, a section of the journal

Frontiers in Microbiology

Received: 28 January 2020 Accepted: 16 April 2020

Published: 03 June 2020

Citation:

Steunou AS, Durand A Bourbon M-L, Babot M, Tambosi R, Liotenberg S and Ouchane S (2020) Cadmium and Copper Cross-Tolerance. $\mathrm{Cu}^{+}$Alleviates $\mathrm{Cd}^{2+}$ Toxicity, and Both Cations

Target Heme and Chlorophyll

Biosynthesis Pathway in Rubrivivax gelatinosus. Front. Microbiol. 11:893.

doi: 10.3389/fmicb.2020.00893
Cadmium, although not redox active is highly toxic. Yet, the underlying mechanisms driving toxicity are still to be characterized. In this study, we took advantage of the purple bacterium Rubrivivax gelatinosus strain with defective $\mathrm{Cd}^{2+}$-efflux system to identify targets of this metal. Exposure of the $\Delta c a d A$ strain to $\mathrm{Cd}^{2+}$ causes a decrease in the photosystem amount and in the activity of respiratory complexes. As in case of $\mathrm{Cu}^{+}$toxicity, the data indicated that $\mathrm{Cd}^{2+}$ targets the porphyrin biosynthesis pathway at the level of HemN, a S-adenosylmethionine and CxxxCxxC coordinated [4Fe-4S] containing enzyme. $\mathrm{Cd}^{2+}$ exposure therefore results in a deficiency in heme and chlorophyll dependent proteins and metabolic pathways. Given the importance of porphyrin biosynthesis, HemN represents a key metal target to account for toxicity. In the environment, microorganisms are exposed to mixture of metals. Nevertheless, the biological effects of such mixtures, and the toxicity mechanisms remain poorly addressed. To highlight a potential cross-talk between $\mathrm{Cd}^{2+}$ and $\mathrm{Cu}^{+}$-efflux systems, we show (i) that $\mathrm{Cd}^{2+}$ induces the expression of the $\mathrm{Cd}^{2+}$-efflux pump CadA and the $\mathrm{Cu}^{+}$detoxification system CopA and Copl; and (ii) that $\mathrm{Cu}^{+}$ions improve tolerance towards $\mathrm{Cd}^{2+}$, demonstrating thus that metal mixtures could also represent a selective advantage in the environment.

Keywords: CadA/ZntA, cadmium/copper, metal homeostasis, metal toxicity, cross-talk, [4Fe-4S], porphyrin biosynthesis

\section{INTRODUCTION}

Metal accumulation, through environmental contamination by anthropogenic release, results in toxicity leading to impaired growth of microorganisms (Nunes et al., 2016). Indeed, excess metal can affect and disrupt different cellular metabolic pathways. Because of their thiophilicity, metals

Abbreviations: BN-PAGE, blue native polyacrylamide gel electrophoresis; DAB, 3,3'-diaminobenzidine tetrahydrochloride; DDM, n-dodecyl- $\beta$-D-maltopyranoside; HRP, horseradish peroxidase; LH-RC, light harvesting-reaction center; PVDF, polyvinylidene difluoride. 
can compete or displace each other in the binding sites of metalloproteins. For instance, copper $\left(\mathrm{Cu}^{+}\right)$, zinc $\left(\mathrm{Zn}^{2+}\right)$ or cadmium $\left(\mathrm{Cd}^{2+}\right)$ represent a standing threat for $\mathrm{Fe}-\mathrm{S}$ proteins in bacteria. They can either directly damage exposed [4Fe-4S] clusters (Macomber and Imlay, 2009) or inhibit components of the iron-sulfur (Fe-S) biogenesis machinery (Tan et al., 2017; Roy et al., 2018; Li et al., 2019). In Escherichia coli, $\mathrm{Cu}^{+}, \mathrm{Zn}^{2+}$ or $\mathrm{Cd}^{2+}$ exert their toxic effects by disrupting the solvent exposed [4Fe-4S] clusters of dehydratases (Macomber et al., 2007; Macomber and Imlay, 2009; Xu and Imlay, 2012). These cations can also compete and prevent iron or iron-sulfur cluster binding in IscA, IscU or ferredoxin in the iron-sulfur cluster biogenesis system (Tan et al., 2017; Roy et al., 2018; Li et al., 2019).

In the human pathogen Neisseria gonorrhoeae, and the photosynthetic bacterium Rubrivivax (R.) gelatinosus, accumulation of $\mathrm{Cu}^{+}$in the cytoplasm affect heme biosynthesis (Azzouzi et al., 2013; Djoko and McEwan, 2013). A hypothesis put forward is that $\mathrm{Cu}^{+}$excess targets HemN, the anaerobic coproporphyrinogen III Oxidase. This

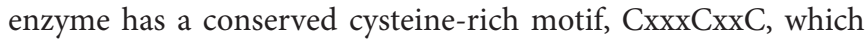
coordinates a solvent $[4 \mathrm{Fe}-4 \mathrm{~S}]$ cluster with an iron that anchors a S-adenosylmethionine (SAM) moiety (Layer et al., 2003). It was suggested that $\mathrm{Cu}^{+}$targets this solvent exposed SAM-[4Fe-4S] cluster, thereby affecting the enzyme activity (Azzouzi et al., 2013; Djoko and McEwan, 2013).

Given the importance of Fe-S clusters and heme metabolism in bacteria but also in eukaryotes, the increase of metal concentration in the environment is therefore challenging to all living organisms. Homeostasis maintenance and detoxification of metal excess are therefore crucial to enable bacterial survival in contaminated environments or in macrophages for pathogenic bacteria (Arguello et al., 2007; von Rozycki and Nies, 2009; Capdevila et al., 2017; Chandrangsu et al., 2017).

The intracellular concentration of metals is tightly regulated at the uptake, storage and/or excretion level (Arguello et al., 2007; von Rozycki and Nies, 2009; Capdevila et al., 2017; Chandrangsu et al., 2017). For metals such as copper, cadmium or silver, efflux pumps are effective detoxification systems that allow bacteria to deal with excess metals in their immediate environment (Arguello et al., 2007; von Rozycki and Nies, 2009; Capdevila et al., 2017; Chandrangsu et al., 2017). Indeed, most free-living bacteria possess efflux system to remove metal excess. Members of $\mathrm{P}_{1 B}$-type ATPases family of heavy metal transporters are universally present in bacteria. They are part of the large superfamily of ATP-driven pumps involved in metal transport across bacterial inner membrane (Arguello et al., 2007). These transporters extrude excess or toxic metal ions such as $\mathrm{Cu}^{+}$, $\mathrm{Zn}^{2+}, \mathrm{Cd}^{2+}$, or $\mathrm{Ag}^{+}$from the cytoplasm to the periplasm in which metal is handled by other detoxifying proteins (Arguello et al., 2007). $\mathrm{Cu}^{+}, \mathrm{Zn}^{2+}$, or $\mathrm{Cd}^{2+}$ efflux ATPase mutants accumulate these cations in their cytoplasm (Legatzki et al., 2003; Gonzalez-Guerrero et al., 2010; Djoko and McEwan, 2013; Lu et al., 2016) and very often display growth inhibition phenotype.

A strain of $R$. gelatinosus (TN414) efficient at removing $\mathrm{Cd}^{2+}$ and $\mathrm{Zn}^{2+}$ from cadmium and zinc contaminated soil has been isolated from paddy fields (Sakpirom et al., 2017). R. gelatinosus $\mathrm{S} 1$ can also grow in medium containing up to $3 \mathrm{mM}$ of cadmium.
The mechanisms governing $\mathrm{Cd}^{2+}$ tolerance are however, not yet known. In this study, we first identified the $\mathrm{Cd}^{2+}$-efflux system to ask which pathways $\mathrm{Cd}^{2+}$, a divalent non-redox active cation, impacts in the absence of an efficient efflux system. Interestingly, it is also shown that $\mathrm{Cd}^{2+}$ induces $\mathrm{Cu}^{+}$homeostasis system and that $\mathrm{Cu}^{+}$alleviates $\mathrm{Cd}^{2+}$ toxicity in $R$. gelatinosus, a phenomenon that could represent a selective advantage for bacteria growing in multiple metal-polluted environment.

\section{MATERIALS AND METHODS}

\section{Bacterial Strains and Growth}

Escherichia coli was grown at $37^{\circ} \mathrm{C}$ in LB medium. R. gelatinosus (S1) was grown at $30^{\circ} \mathrm{C}$, in the dark aerobically (high oxygenation: $250 \mathrm{ml}$ flasks containing $20 \mathrm{ml}$ medium) and microaerobically (low oxygenation: $50 \mathrm{ml}$ flasks filled with $50 \mathrm{ml}$ medium) or in light (photosynthetically in filled tubes with residual oxygen in the medium) in malate growth medium. Antibiotics were used at the following concentrations: kanamycin (Km), ampicillin and trimethoprim (Tp) at $50 \mu \mathrm{g} / \mathrm{ml}$, tetracycline at $2 \mu \mathrm{g} / \mathrm{ml}$. Bacterial strains and plasmids are listed in Supplementary Table SI. Growth inhibition curves were monitored at $\mathrm{OD}_{680 \mathrm{~nm}}$ with measurements taken every $15 \mathrm{~min}$ for $24 \mathrm{~h}$ using a Tecan Infinite M200 luminometer (Tecan, Mannerdorf, Switzerland) for aerobic condition. For photosynthesis conditions, strains were grown as described above and OD was measured after $24 \mathrm{~h}$ using the Tecan luminometer. Inhibition growth experiments were done in triplicates starting from a three diluted culture $\left(\mathrm{OD}_{680}\right.$ at 0.02$)$.

\section{Gene Cloning and Plasmid Constructions for Allele Replacement}

Standard methods were performed according to Sambrook et al. (1989) unless indicated otherwise. To inactivate $\operatorname{cadA}$, a $1.8 \mathrm{~kb}$ fragment was amplified using the primers cadAF1 and cadAR1 (Supplementary Table SII) and cloned into the PCR cloning vector pGEM-T to give $\mathrm{pGcadA}$. cadA gene was inactivated by deletion of $0.8 \mathrm{~kb}$ fragment and the insertion of the Tp cassette at the NarI sites within the cadA coding sequence. The resulting recombinant plasmid was designated pGcadA:Tp. Furthermore, a plasmid (pB106) containing the full $c a d A$ and $c a d R$ genes was also isolated from the DNA library. A $6.6 \mathrm{~kb}$ fragment containing cadA was subcloned from pB106 in pBBR1MCS-2 at the KpnISacI sites. The resulting plasmid was designated pBKCadA. cadR was PCR cloned using primers cadRF1 and cadRR1 in pGemT plasmid. To inactivate $c a d R$, the $1.2 \mathrm{~kb} \mathrm{Km}$ cassette was inserted in the StuI site within $c a d R$ in the pGcadR plasmid. To generate HemN-H6 fusion, hemN was amplified from wild-type genomic DNA using primers hemN-NdeI and hemN-XhoI and cloned in the corresponding sites within pET-28b.

\section{Gene Transfer and Strain Selection}

Transformation of $R$. gelatinosus cells was performed by electroporation (Ouchane et al., 1996). The plasmid pGcadA:Tp was used to transform the wild-type, $\operatorname{cop} A^{-}, \Delta \operatorname{copI}$, or 
copA- $H_{6}$ strains. Transformants were selected on malate plates supplemented with appropriate antibiotics under aerobic conditions. Following transformant selection, template genomic DNA was prepared from the ampicillin sensitive transformants and confirmation of the antibiotic resistance marker's presence at the desired locus was performed by PCR. Finally, selected colonies were spotted on metal containing plates to confirm their metal sensitive phenotype. Plasmid phem $N-H_{6}$ was used to transform the wild-type strain to generate the $\mathrm{HemN}-\mathrm{H}_{6}$ strain. Clones were selected on kanamycin plates.

\section{Membrane and Soluble Protein Preparation}

The membranes or solubles fractions were prepared by cell disruption with a French press in $0.1 \mathrm{M}$ sodium phosphate buffer ( $\mathrm{pH}$ 7.4) containing $1 \mathrm{mM}$ phenylmethylsulfonyl fluoride, followed by differential centrifugation. Samples were subjected to a low speed centrifugation step $\left(25,000 \mathrm{~g}, 30 \mathrm{~min}, 4^{\circ} \mathrm{C}\right)$ and supernatants were subjected to ultracentrifugation $(200,000 \mathrm{~g}$, $1 \mathrm{~h} 30,4^{\circ} \mathrm{C}$ ) to purify the soluble proteins and collect the membrane fraction in the pellets.

The membranes were then resuspended in the same buffer. Protein concentration was estimated using the bicinchoninic acid assay (Sigma) with bovine serum albumin as a standard. Periplasmic fractions were purified as previously described by Durand et al. (2015).

\section{Spectrophotometric Measurements}

Absorption spectroscopy was performed with a Cary 500 spectrophotometer. For difference spectra (reduced minus oxidized), total pigments were extracted from cell pellets or membranes with acetone-methanol (7/2 [vol/vol]). For each sample, the spectrum was collected on oxidized sample upon addition of $50 \mu \mathrm{M} \mathrm{K} \mathrm{K}_{6} \mathrm{Fe}(\mathrm{CN})_{3}$. The sample was reduced by addition of dithionite (few crystals), and the spectrum was collected to generate the reduced minus oxidized spectrum.

\section{Blue-Native Gel Electrophoresis}

To assay $c b b_{3}$ and succinate dehydrogenase activities, wild-type and $\Delta c a d A$ strains were grown microaerobically. Membranes were prepared as previously described (Khalfaoui Hassani et al., 2010). Blue-native polyacrylamide gel (BN-PAGE) electrophoresis and in gel-Cox activity assays (DAB staining) were performed as described in (Khalfaoui Hassani et al., 2010) and succinate dehydrogenase activity was assayed using succinate and NBT (Nitroblue tetrazolium) as described for the succinateNBT reductase assay in reference Wittig et al. (2007).

\section{Western Blot and Immunodetection}

Equal amount of proteins or disrupted cells $\left(\mathrm{OD}_{680 \mathrm{~nm}}=1\right)$ were separated by SDS-PAGE (15\% polyacrylamide) and further transferred to a Hybond ECL PVDF membrane, (GE Healthcare). Coomassie blue of the SDS gels are shown in Supplementary Material. Membranes were then probed with the HisProbe-HRP (from Pierce) according to the manufacturer instruction and positive bands were detected using a chemiluminescent HRP substrate according to the method of Haan and Behrmann (2007). Image capture was performed with a ChemiDoc camera system (Biorad).

\section{RESULTS}

\section{The P-type ATPase CadA Is the Primary Cadmium Tolerance Element in $R$. gelatinosus}

Cadmium tolerance in bacteria usually involves the metal efflux pump $\mathrm{P}_{1 B}$-type ATPase CadA (ZntA) protein that translocates cadmium from the cytoplasm to the periplasm (Rensing et al., 1998). A gene (hereafter referred to as cadA) encoding a putative ATPase involved in $\mathrm{Zn}^{2+}$ or $\mathrm{Cd}^{2+}$ efflux was identified in $R$. gelatinosus genome. Sequence analyses showed high similarities with putative heavy metal translocating $\mathrm{P}_{1 B}$-type ATPases from $\beta$-proteobacteria (Supplementary Figure S1). In addition to conserved structural features and motifs in the ATPase sequence, an N-terminal 30 amino acids stretch consisting of 14 histidines and 7 acidic residues, flanked by two $\mathrm{CxxxC}$ motifs were found in $R$. gelatinosus CadA (Supplementary Figure S1). This N-terminal cytoplasmic stretch could play a role in metal binding and transport regulation as reported for other metal transporting ATPases (Mana-Capelli et al., 2003; Baekgaard et al., 2010). A gene (referred to as $c a d R$ ) encoding a MerR regulator protein (CadR) was found upstream $\operatorname{cad} A$. To ascertain the role of CadA in $\mathrm{Cd}^{2+}$ tolerance, the $\triangle c a d A$ deletion strain was generated and its ability to grow on solid medium in presence of $\mathrm{CdCl}_{2}$ was tested in comparison with wild-type strain under aerobic respiration and photosynthesis conditions (Figure 1). When challenged with $\mathrm{Cd}^{2+}$, the growth of $\triangle \mathrm{cadA}$ strain is inhibited with 100 or $250 \mu \mathrm{M} \mathrm{CdCl} 2$ under aerobic or photosynthesis conditions, respectively. In contrast, the wild-type strain was still able to grow in presence of 1.5 or $3 \mathrm{mM} \mathrm{CdCl}_{2}$ (Figure 1B). The tolerance towards $\mathrm{Cd}^{2+}$ was restored by the expression of the wild-type copy of cadA gene in trans in $\triangle$ cadA strain (Supplementary Figure S2). Growth inhibition by $\mathrm{Cd}^{2+}$ of these strains was also assessed in liquid medium in the presence of increasing $\mathrm{CdCl}_{2}$ concentration. Whereas growth of the wild-type strain remained unaffected under both conditions, growth of $\triangle c a d A$ mutant was reduced starting at $150 \mu \mathrm{M}$ or $50 \mu \mathrm{M} \mathrm{CdCl}_{2}$ under photosynthesis (Figure 1C) and respiration (Figure 1D) conditions, respectively. $\Delta c a d A$ mutant was also sensitive to excess $\mathrm{Zn}^{2+}$ as shown by growth inhibition on plates of the wild-type and $\triangle c a d A$ grown in the presence of $\mathrm{CdCl}_{2}, \mathrm{ZnSO}_{4}$ or $\mathrm{CuSO}_{4}$ (Supplementary Figure S3A). Similarly, dose response and growth curves in liquid media (Supplementary Figures S3B-D) confirmed that cadA was also required for full zinc resistance. We should note that $\Delta$ cadA was more tolerant to $\mathrm{Zn}^{2+}$ than $\mathrm{Cd}^{2+}$ probably because under $\mathrm{Zn}^{2+}$ excess, $\mathrm{Zn}^{2+}$ uptake (ZnuABC transporter) could be limited by $\mathrm{Zur}$ regulator and other $\mathrm{Zn}^{2+}$-efflux systems like CzcCBA could mediate $\mathrm{Zn}^{2+}$ efflux (Arguello et al., 
2007; von Rozycki and Nies, 2009; Capdevila et al., 2017; Chandrangsu et al., 2017). Genes encoding these proteins are present in $R$. gelatinosus genome, but their role was not investigated yet. These data confirmed that $\operatorname{cadA}$ gene encodes for the $\mathrm{Cd}^{2+} / \mathrm{Zn}^{2+}$-efflux ATPase CadA, required for $\mathrm{Cd}^{2+}$ (and involved in $\mathrm{Zn}^{2+}$ ) tolerance in $R$. gelatinosus, and that the $\triangle$ cadA mutant is more sensitive to cadmium under respiratory conditions.

\section{Induction of CadA in Response to Excess $\mathrm{Cd}^{2+}$ Involves the MerR-Type Transcriptional Regulator CadR}

To cope with excess toxic metal exposure, bacteria usually induce the expression of metal detoxification proteins including the efflux ATPases. To gain better insight into the expression profile of CadA in response to excess $\mathrm{Cd}^{2+}$, we analyzed the expression of CadA by Western blot in the wild-type and $\Delta$ cadA strains grown under photosynthesis condition in presence of increasing $\mathrm{CdCl}_{2}$ concentration. The presence of the histidine stretch within CadA N-terminus sequence allowed the detection of CadA on Western blot using the horseradish peroxidase (HRP)-conjugated HisProbe. As shown in Figure 2A, addition of $150 \mu \mathrm{M}$ or $1 \mathrm{mM} \mathrm{CdCl}_{2}$ to the medium during wildtype growth resulted in a significant increase in the amount of an $80 \mathrm{kDa}$ protein, likely corresponding to CadA. This band was not detected in the $\triangle c a d A$ cells grown without or with the addition of $150 \mu \mathrm{M} \mathrm{CdCl}$. To confirm that this band was indeed CadA, the $\triangle c a d A$ complemented strain was also subjected to $\mathrm{Cd}^{2+}$ stress and Western blot showed the expression and induction of the $80 \mathrm{kDa}$ band encoded by $\operatorname{cad} A$ gene on the replicative plasmid (Supplementary Figure S2B). These findings demonstrated that CadA is induced by cadmium Unexpectedly, in addition to CadA induction, $\mathrm{Cd}^{2+}$ also induced an increase in the amount of the periplasmic $\mathrm{Cu}^{+}$tolerance protein CopI (Durand et al., 2015) in both wild-type and $\Delta$ cadA cells suggesting a putative role of CopI in $\mathrm{Cd}^{2+}$ tolerance and very likely a cross talk between $\mathrm{Cu}^{+}$and $\mathrm{Cd}^{2+}$ (see below). To unequivocally show that the $\mathrm{Cd}^{2+}$-induced band correspond to CopI, we generated a mutant $(\triangle \operatorname{cad} A-\Delta c o p I)$ in which $\operatorname{cad} A$ and copI were deleted, and probed the presence of CopI in the periplasmic fractions. As shown in Figure 2B, while CopI was induced in $\triangle c a d A$ under $\mathrm{Cd}^{2+}$ excess, the band was absent in the $\Delta c a d A \_\Delta c o p I$ mutant showing that the cadmium-induced band correspond to CopI.

It has been reported that the transcription regulator CadR/ZntR recognizes a palindromic sequence in the promoter region of $c a d A / z n t A$ genes (Singh et al., 1999). In the intergenic sequence (54 bp) between $c a d A$ and $c a d R$ (Figure 1), an inverted repeat sequence $\left({ }^{-27}\right.$-ACCCGCTACAGGGT- $\left.{ }^{-13}\right)$ might allow the binding of regulatory proteins was identified. To further highlight the role of CadR, the gene was inactivated and the resulting $c a d R^{-}$strain was shown to be sensitive to cadmium (Supplementary Figure S4) suggesting its involvement in cadA expression. To unambiguously show the role of $c a d R$ in $\operatorname{CadA}$ expression, we checked the expression level of CadA in the wildtype and the $\mathrm{cadR}^{-}$strains challenged with excess $\mathrm{Cd}^{2+}$. For this

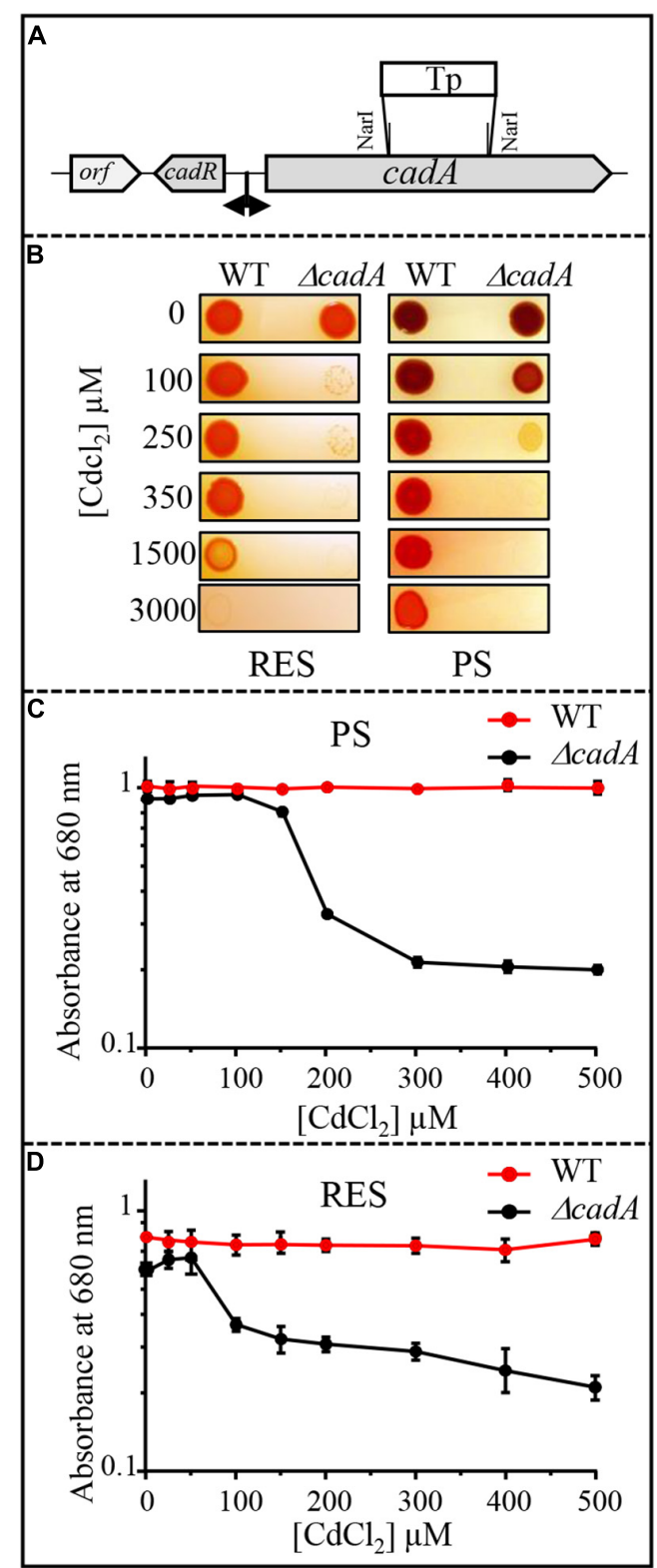

FIGURE 1 | (A) Genetic organization of the cadAR locus in $R$. gelatinosus. To inactivate cadA, the $\mathrm{Narl}$ fragment was replaced by antibiotic resistance Tp cassette. (B) Growth phenotype of the wild-type (WT) and $\triangle$ cadA on solid medium supplemented with $\mathrm{CdCl}_{2}$. Plates were incubated under aerobic respiration (RES) in the dark or under photosynthesis (PS) for $24 \mathrm{~h}$ at $30^{\circ} \mathrm{C}$ prior to photography. (C,D) Growth inhibition of the WT and $\triangle$ cadA mutant challenged with increasing $\mathrm{CdCl}_{2}$ concentrations under photosynthesis (PS) (C) and respiration (RES) (D) conditions. Cells were grown for $24 \mathrm{~h}$ at $30^{\circ} \mathrm{C}$ before $\mathrm{OD}_{680 \mathrm{~nm}}$ measurement. The error bars represent the standard deviation of the mean of 3 independent experiments.

purpose, cells were grown overnight under photosynthesis in the presence of increasing $\mathrm{CdCl}_{2}$ concentration and CadA expression profile was assessed by Western blot. In contrast to the wild-type, overnight growth of $c a d R^{-}$cells was inhibited beyond $600 \mu \mathrm{M}$ $\mathrm{CdCl}_{2}$. Western blot analysis confirmed that CadA is induced 


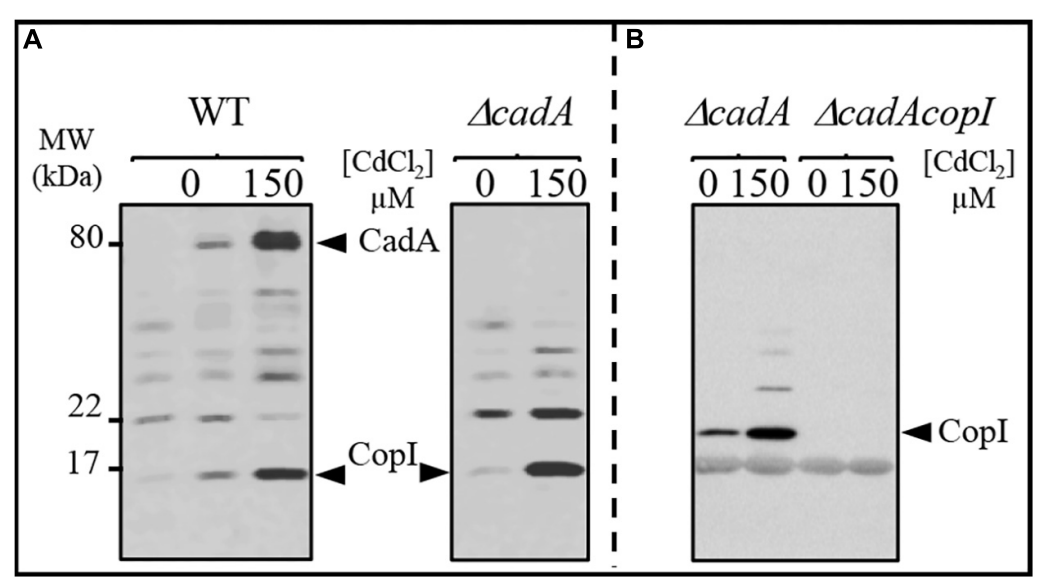

FIGURE 2 | Expression profile of CadA and Copl in R. gelatinosus wild-type (WT) and $\Delta$ cadA cells challenged with Cd ${ }^{2+}$. Cells were grown overnight (18 h) under photosynthesis and total protein extract from the same amount of cells $\left(\mathrm{OD}_{680 \mathrm{~nm}}=0.1\right)$ were separated on a $15 \%$ Tris-glycine SDS-PAGE (A). Periplasmic fractions were purified from $\Delta$ cadA and $\Delta c a d A \_\Delta c o p /$ cells challenged or not with $\mathrm{Cd}^{2+}$ and separated on a $15 \%$ Tris-glycine SDS-PAGE (B). Proteins were visualized after Western blotting using the HRP-HisProbe (Pierce).

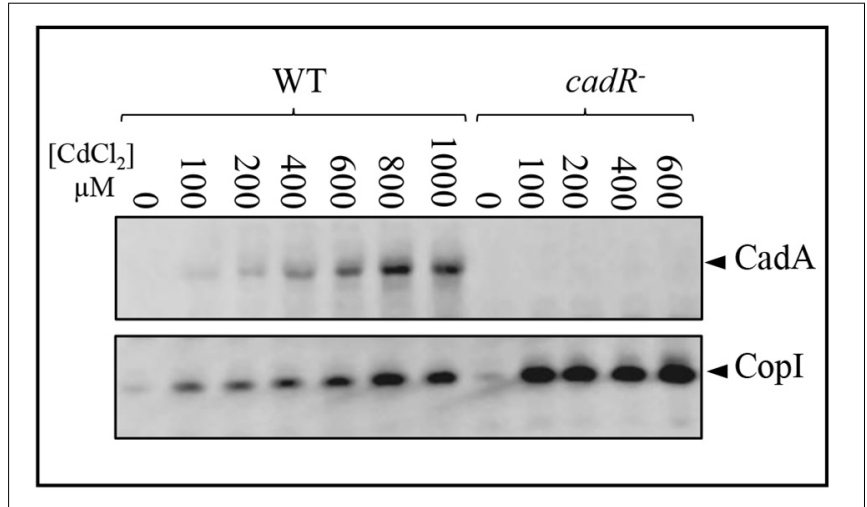

FIGURE 3 | Expression level of CadA and Copl in R. gelatinosus wild-type (WT) and cadR- mutant cells challenged with increasing concentration of $\mathrm{CdCl}_{2}$. Cells were grown overnight (18 h) under photosynthetic condition. Total protein extract from the same amount of cells $\left(\mathrm{OD}_{680 \mathrm{~nm}}=0.1\right)$ were separated on a 15\% Tris-glycine SDS-PAGE. Proteins were visualized after Western blotting using the HRP-HisProbe.

with increasing concentration of $\mathrm{CdCl}_{2}$ (Figure 3) in the wildtype and this induction is CadR-dependent since CadA was not detected in $c a d R^{-}$cells. In conclusion, these data showed that the CadA efflux ATPase is required for cadmium detoxification and its expression is induced by $\mathrm{CdCl}_{2}$ under the control of CadR. Note that the $c a d R^{-}$mutant tolerates a higher cadmium concentration than the $\triangle c a d A$ mutant, but less than the wildtype (Supplementary Figure S4). This difference could be due to a low expression of CadA (undetectable on Western blot) in $c a d R^{-}$, but sufficient enough to warrant tolerance toward low cadmium concentrations. The Western blot also confirmed the induction of CopI expression in response to $\mathrm{Cd}^{2+}$ stress and showed that induction of CopI by $\mathrm{Cd}^{2+}$ occurred, even in the absence of CadR.

\section{Cadmium Effect on Photosynthesis and Respiratory Membrane Complexes}

The toxic effect of $\mathrm{Cu}^{+}$on photosynthesis and respiration in $R$. gelatinosus was previously assessed in the $\mathrm{Cu}^{+}-\mathrm{P}_{1 B^{-}}$ type ATPase efflux mutant $\operatorname{cop} A^{-}$(Azzouzi et al., 2013; Liotenberg et al., 2015). Because photosynthetic organisms can also be exposed to $\mathrm{Cd}^{2+}$ in their environment, we took advantage of the $\triangle$ cadA strain that should likely accumulate $\mathrm{Cd}^{2+}$ in the cytoplasm, to ask whether $\mathrm{Cd}^{2+}$ affects protein complexes and cytochromes involved in photosynthesis and microaerobic respiration. Membranes from the wild-type and $\Delta c a d A$ cells grown microaerobically in medium supplemented or not with $100 \mu \mathrm{M} \mathrm{Cd}^{2+}$ were enriched and the amount of photosynthetic complexes (RC-LH $860 \mathrm{~nm}$ and $800 \mathrm{~nm}$ ) was assessed with UV-visible absorbance spectra. In contrast to the wild-type, the amount of the photosynthetic complexes was shown to significantly decrease in the membrane of $\Delta$ cadA cells exposed to $\mathrm{Cd}^{2+}$ (Figure 4A). We also performed redox spectral analyses (reduced minus oxidized spectra) to checked the effect of $\mathrm{Cd}^{2+}$ on cytochromes $c$ (peak at $552 \mathrm{~nm}$ ) and b (peak at $560 \mathrm{~nm}$ ) in these membranes by comparing the total cytochrome content in the wild-type and $\triangle c a d A$ membranes (Figure 4B). Comparable spectra were recorded for $\mathrm{Cd}^{2+}$ treated and untreated wildtype membrane. Unlike the wild-type, in the $\Delta$ cadA cells, $\mathrm{Cd}^{2+}$ addition resulted in a drastic decrease of cytochrome $c$ and $b$ content within the membranes.

BN-PAGE analysis confirmed the decreased amount of reaction centre and light harvesting antenna (RC-LH) in the $\mathrm{Cd}^{2+}$ stressed $\triangle c a d A$ mutant membranes (Figure 4C). Furthermore, cytochrome $c$ oxidase in-gel assay revealed comparable amount of active cytochrome $c$ oxidase $c b b_{3}$ in the wild-type membrane from cells grown with or without $\mathrm{Cd}^{2+}$; whereas in $\Delta c a d A$ membrane, the $c b b_{3}$ active band decreased significantly in the $\mathrm{Cd}^{2+}$ stressed mutant. Concomitantly, succinate-NBT reductase in-gel assay revealed an active band, 


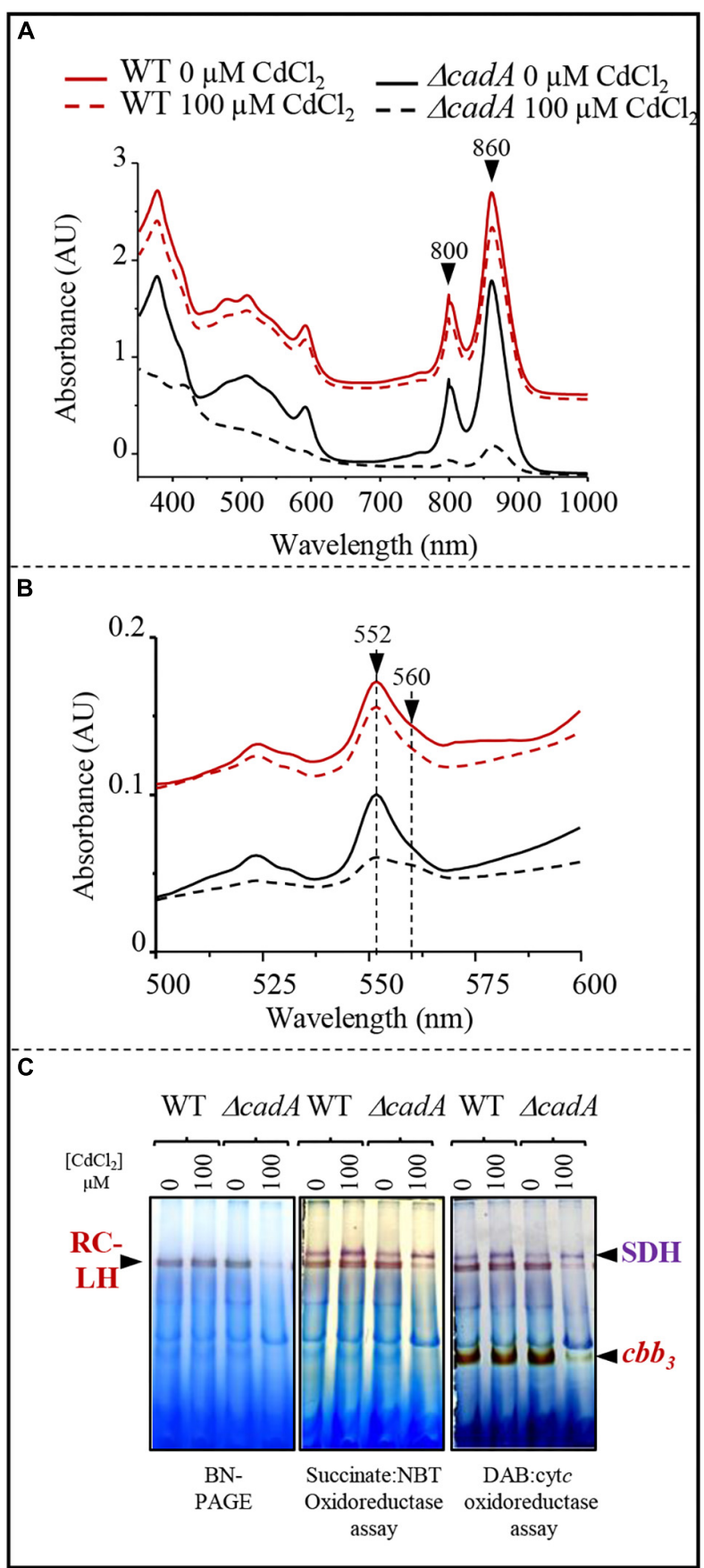

FIGURE 4 | Cadmium effect on photosynthesis and respiratory membrane complexes in the wild-type (WT) and $\Delta$ cadA mutant grown overnight (18 h) under microaerobic condition. (A) Effect of $\mathrm{CdCl}_{2}$ on photosystem (860-800 nm) amount in the membranes. (B) Difference (reduced minus oxidized) pyridine haemochrome spectra of WT (red) and $\Delta$ cadA (black) membranes with $100 \mu \mathrm{M}$ (dashed lines) or without cadmium (lines). (C) $c b b_{3}$ cytochrome $c$ oxidase and succinate dehydrogenase $(\mathrm{SDH})$ in-gel activity assays. Equal amount of DDM-solubilized membrane proteins from wild-type (WT) and $\Delta$ cadA cells grown without or in the presence of $150 \mu \mathrm{M} \mathrm{CdCl}_{2}$ were separated on 3-12\% acrylamide-bisacrylamide gradient BN-PAGE. Gels were first assayed for $c b b_{3}$ cytochrome $c$ oxidase activity (DAB staining) and subsequently assayed for SDH activity (Succinate/NBT). The photosynthetic $\mathrm{RC}$-LH complexes are also visible on the gel thanks to their photopigments. likely corresponding to $\mathrm{SDH}$, in the wild-type and $\triangle \mathrm{cadA}$ membranes. This band increased slightly in the presence of $\mathrm{Cd}^{2+}$ in both strains. However, the activity was also slightly reduced in $\Delta c a d A$ membranes compared to the wild-type membranes (Figure 4C). The decrease in active cytochrome $c$ oxidase $c b b_{3}$ was more pronounced than the SDH. The SDH complex requires only one heme per complex while the $c b b_{3}$ oxidase requires five hemes for its assembly and activity.

Photosynthetic and respiratory complexes require chlorophylls and heme cofactors respectively for their assembly and activity. The decreased level of these complexes in presence of excess $\mathrm{Cd}^{2+}$ could be attributed to a decreased amount of cofactors under $\mathrm{Cd}^{2+}$ stress condition in the $\Delta$ cadA mutant. The total heme and chlorophylls were extracted from cells exposed or not to $\mathrm{Cd}^{2+}$ and dithionite-reduced and ferricyanide-oxidized pyridine hemochrome spectra were recorded. The reduced minus oxidized spectra showed a comparable amount of heme (peaks $\alpha$ and $\beta$ at $550 \mathrm{~nm}$ and $520 \mathrm{~nm}$ respectively) and bacteriochlorophylls $(756 \mathrm{~nm})$ for photosynthetic grown wild-type strain in presence/absence of $\mathrm{Cd}^{2+}$ in these samples (Figure 5A). The $\Delta$ cadA mutant cells stressed by $100 \mu \mathrm{M}$ of $\mathrm{Cd}^{2+}$ presented a strong decrease of the heme and bacteriochlorophylls content compared to the unstressed mutant strain (Figure 5B). Heme and chlorophyll share the same biosynthesis pathway down to protoporphyrin IX. An effect of cadmium on the porphyrin biosynthesis pathway upstream protoporphyrin IX would then affect concomitantly heme and chlorophyll biosynthesis.

\section{Cadmium Excess Is Associated With an Accumulation of Coproporphyrin III}

The wild-type strain and the $\Delta c a d A$ mutant were subjected to increasing sub-lethal concentrations of $\mathrm{CdCl}_{2}(0-150 \mu \mathrm{M}$ $\mathrm{CdCl}_{2}$ ) under photosynthetic growth conditions. No effect of excess $\mathrm{CdCl}_{2}$ was observed on the wild-type cells (not shown). Conversely, for the $\Delta c a d A$ cells, growth was affected by increasing $\mathrm{CdCl}_{2}$ concentration and a UV-fluorescent pigment was released in the spent medium as a $\mathrm{CdCl}_{2}$ concentrationdependent manner (Figure 6A). This phenotype also seen under microaerobic conditions, is presumably due to the excretion of porphyrin intermediate and is reminiscent of the $\operatorname{cop} A^{-}$ strain one when exposed to $\mathrm{Cu}^{+}$(Azzouzi et al., 2013). The spent medium of the $\triangle c a d A$ strain was therefore compared to that of wild-type and $\operatorname{cop} A^{-}$strains using UV-Vis absorbance spectra (Figure 6B). In view of these spectra, the $\triangle c a d A$ strain extrudes the same pigment as the $\operatorname{cop} A^{-}$strain exposed to $\mathrm{Cu}^{+}$. Two absorbance peaks in the Soret region at 371 and $395 \mathrm{~nm}$ with minor peaks at 501, 537, and $553 \mathrm{~nm}$ were observed. These peaks are characteristic of coproporphyrin III (oxidized coproporphinogen III), a protoporphyrin IX precursor. The presence of coproporphyrin III in the medium may correlate with a decreased amount of chlorophylls and heme in the $\triangle c a d A$ cells exposed to $\mathrm{Cd}^{2+}$. To ascertain this assumption, UV-vis spectra were recorded on total pigments extracted from wild-type and $\Delta c a d A$ strains grown with $100 \mu \mathrm{M}$ $\mathrm{CdCl}_{2}$ or from $\operatorname{cop} A^{-}$strain grown with $50 \mu \mathrm{M} \mathrm{CuSO}_{4}$ 


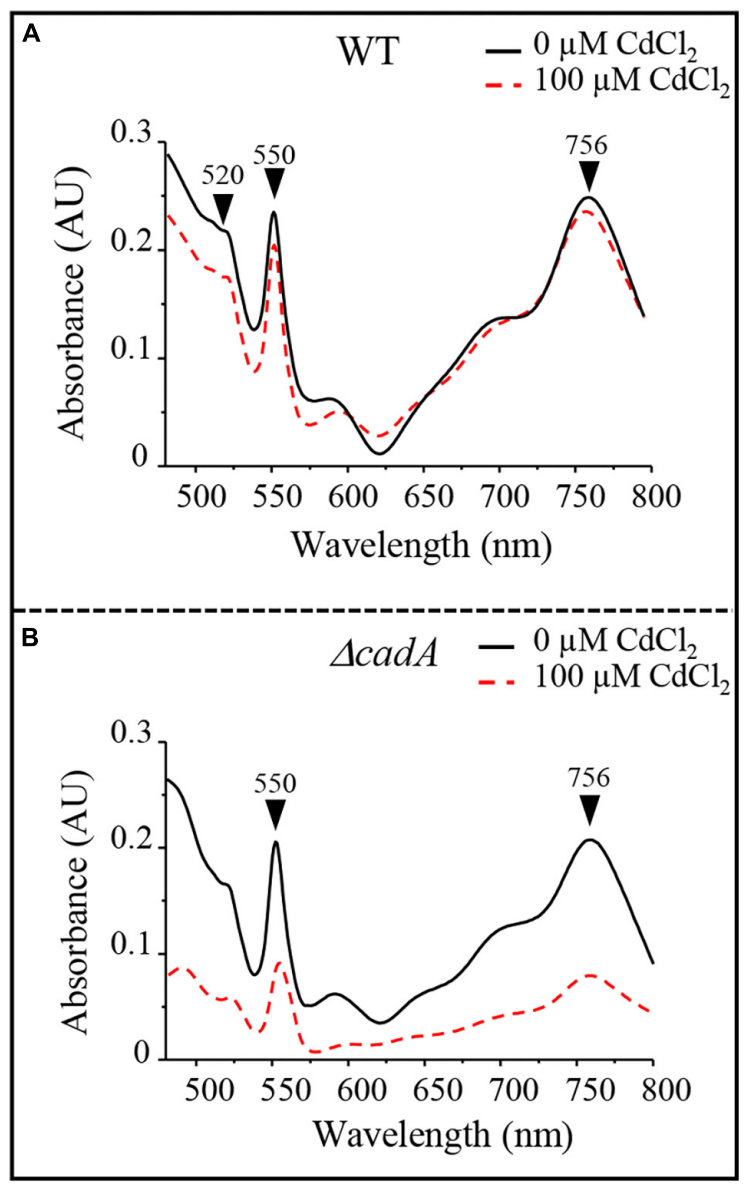

FIGURE 5 | Cadmium effect on total heme $(550 \mathrm{~nm})$ and bacteriochlorophyll $(756 \mathrm{~nm})$ content in the wild-type (WT) (A) and $\triangle$ cadA strain (B) grown by photosynthesis for $18 \mathrm{~h}$ in the presence of $\mathrm{CdCl}_{2}$.

under the same conditions. In both $\triangle c a d A$ and $\operatorname{cop} A^{-}$strains, the addition of $\mathrm{CdCl}_{2}$ or $\mathrm{CuSO}_{4}$ respectively to the growth medium correlated with a decrease in the bacteriochlorophyll a content (peak at $770 \mathrm{~nm}$ ) and an increase of the $395 \mathrm{~nm}$ peak (Figure 6C). In contrast, in the wild-type strain grown in the presence of $100 \mu \mathrm{M} \mathrm{CdCl}$, the higher amount of bacteriochlorophyll $a$ correlated with the absence of the $395 \mathrm{~nm}$ peak in the extract (Figure 6C). These data confirm the accumulation of coproporphyrin III and reflects the decrease of bacteriochlorophyll $a$ and heme under photosynthetic and microaerobic conditions in $\Delta c a d A$ cells exposed to $\mathrm{Cd}^{2+}$ as previously reported for the $\operatorname{cop} A^{-}$mutant exposed to excess $\mathrm{CuSO}_{4}$. As for $\mathrm{Cu}^{+}$toxicity, accumulation of coproporphyrin III in the $\triangle$ cadA strain when stressed with $\mathrm{Cd}^{2+}$ suggested that excess $\mathrm{Cd}^{2+}$ affected the enzyme for which coproporphyrinogen III is a substrate. We therefore assumed that $\mathrm{Cd}^{2+}$ targets the coproporphyrinogen III oxidase $\mathrm{HemN}$ in the porphyrin biosynthesis pathway. This is the first in vivo demonstration that, as oxygen and $\mathrm{Cu}^{+}, \mathrm{Cd}^{2+}$ affects the porphyrin biosynthesis pathway presumably at the level of the SAM and [4Fe-4S] containing HemN enzyme.

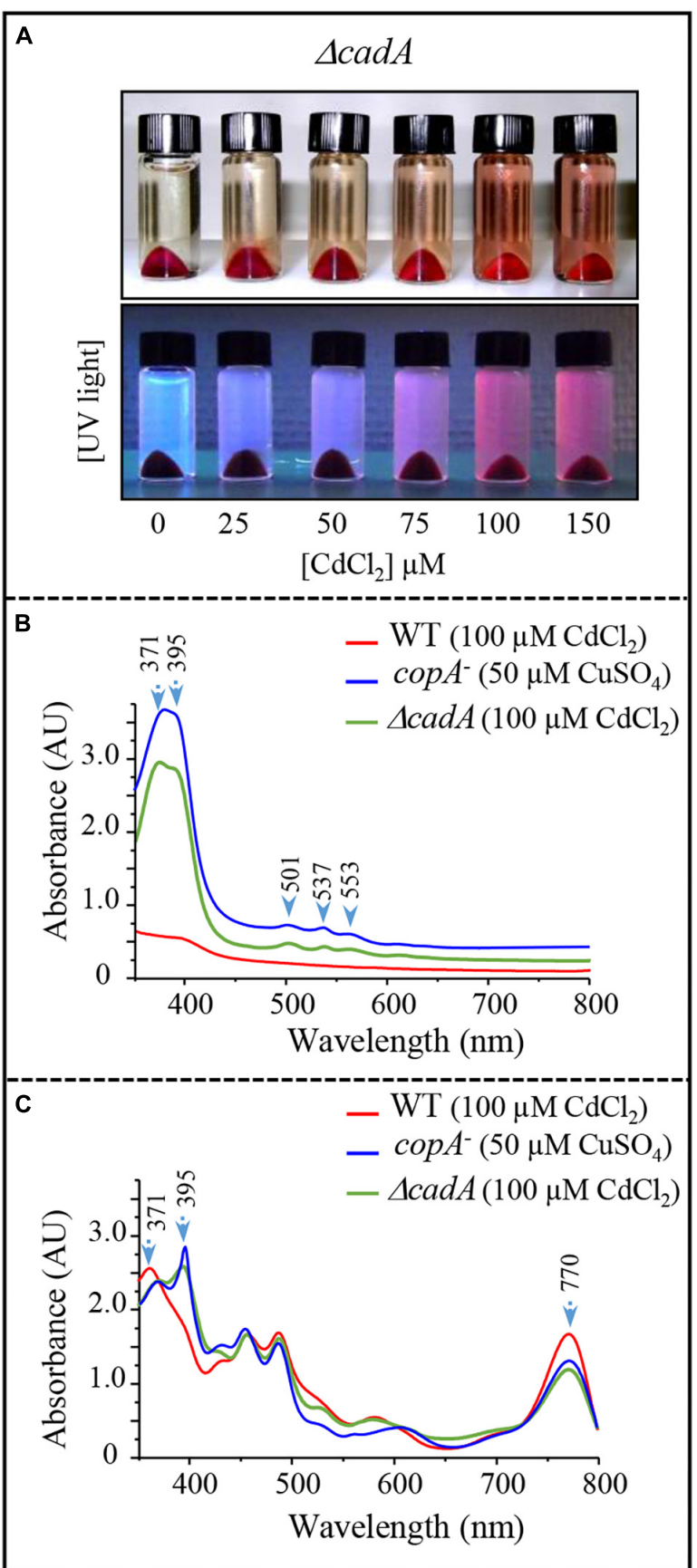

FIGURE 6 | Effect of cadmium on photosynthetic growth in the $\Delta$ cadA strain and characterization of the pigment extruded in the culture medium. (A) Phenotype of the $\triangle$ cadA mutant grown in the presence of increasing $\mathrm{CdCl}_{2}$ concentration. Appearance of coproporphyrin III in the spent medium under visible and UV light. (B) UV-visible absorption spectra of the spent medium from the wild-type and $\Delta c a d A$ strain grown with $100 \mu \mathrm{M} \mathrm{CdCl}_{2}$, in comparison with the spent medium of CopA- strain that accumulates coproporphyrin III (395-371 nm) when grown in the presence of $50 \mu \mathrm{M}$ $\mathrm{CuSO}_{4}$. (C) Absorption spectra of total pigment extract from membranes of the wild-type, $\Delta$ cadA cells grown with $100 \mu \mathrm{M} \mathrm{CdCl}_{2}$ and $\mathrm{copA}^{-}$cells grown with $50 \mu \mathrm{M} \mathrm{CuSO}_{4}$. The spectra show the decrease in the amount of bacteriochlorophyll a $(770 \mathrm{~nm})$ in $\triangle \mathrm{cad} A$ and cop $A^{-}$mutants and reveal the presence of coproporphyrin III in these cells. 


\section{HemN Is a Target of $\mathrm{Cd}^{2+}$ and $\mathrm{Cu}^{+}$ Toxicity in $R$. gelatinosus}

Accumulation of coproporphyrin III in the $\Delta c a d A$ strain when exposed to excess cadmium, or in the CopA defective strains when challenged with excess copper both in $R$. gelatinosus and N. gonorrhoea, strongly suggests that HemN activity is affected by excess metal (Azzouzi et al., 2013; Djoko and McEwan, 2013). Inactivating the $[4 \mathrm{Fe}-4 \mathrm{~S}]$ of $\mathrm{HemN}$ by $\mathrm{Cd}^{2+}$ or $\mathrm{Cu}^{+}$would be consistent with the published evidences showing that $\mathrm{Cd}^{2+}$ or $\mathrm{Cu}^{+}$damage exposed [4Fe-4S] in dehydratases (Macomber and Imlay, 2009; Xu and Imlay, 2012). Attempt to express and purify HemN of $R$. gelatinosus and N. gonorrhoea (Djoko and McEwan, 2013) in E. coli to assess the effect of metal on the enzyme activity were unfortunately unsuccessful. Therefore, to provide direct evidence that $\mathrm{Cd}^{2+}$ or $\mathrm{Cu}^{+}$damage HemN, we hypothesized that the amount of the enzyme would decrease if the [4Fe-4S] cluster is damaged by excess $\mathrm{Cu}^{+}$or $\mathrm{Cd}^{2+}$. To test this assumption, we generated a strain in which the wild-type hem $N$ gene was substituted by a histidine tagged copy on the chromosome. In this strain, the hem $N-H_{6}$ gene is under its own FNRregulated promoter and should therefore be inducible under micro-aerobic and photosynthesis conditions. This strain was subjected to elevated concentrations of $\mathrm{CdCl}_{2}$ or $\mathrm{CuSO}_{4}$ and the amount of $\mathrm{HemN}-\mathrm{H}_{6}$ in the soluble fraction was assessed on Western blot.

A band of $54 \mathrm{kDa}$ likely corresponding to $\mathrm{HemN}_{-} \mathrm{H}_{6}$ was detected on Western blot in the soluble fraction of HemN$\mathrm{H}_{6}$ strain but not in the wild-type soluble fraction (Figure 7). This band was however significantly decreased in the soluble fractions purified from $\mathrm{HemN}-\mathrm{H}_{6}$ strain grown in the medium

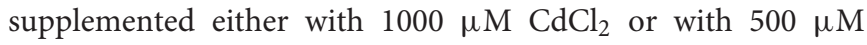
$\mathrm{CuSO}_{4}$ (Figure 7). In contrast to the decrease of $\mathrm{HemN}-\mathrm{H}_{6}$, CopI protein expression was increased in presence of $\mathrm{Cd}^{2+}$ and highly increased by $\mathrm{Cu}^{+}$as expected in these samples (Figure 7), confirming the $\mathrm{Cd}^{2+}$ and $\mathrm{Cu}^{+}$stress status encountered by these cells. These results, clearly demonstrated that in vivo, HemN stability is affected by excess $\mathrm{Cd}^{2+}$ and $\mathrm{Cu}^{+}$, thus elucidating the effect of metal excess on heme biosynthesis and the cause of coproporphyrin III accumulation.

\section{Cadmium and Copper Cross-Tolerance: Copl Is Involved in Cadmium Tolerance}

On Western Blot, we observed an increase of the periplasmic copper tolerance protein CopI with the addition of $\mathrm{CdCl}_{2}$ in both wild-type and $\triangle c a d A$ cells (Figure 2). This CopI induction, in presence of $150 \mu \mathrm{M} \mathrm{CdCl}_{2}$, is higher in the $\Delta c a d A$ mutant than in the wild-type, very likely resulting from $\mathrm{Cd}^{2+}$ accumulation in the cytoplasm of the $\triangle c a d A$ strain. CopI induction by $\mathrm{Cd}^{2+}$ suggested a cross-talk between the $\mathrm{Cd}^{2+}$ and $\mathrm{Cu}^{+}$response systems and a role of CopI and/or the copper detoxification system in $\mathrm{Cd}^{2+}$ response. A band at about $22 \mathrm{kDa}$ apparent molecular weight was also noticeably induced in the $\Delta$ cadA mutant. This band corresponds to the cytosolic superoxide dismutase SodB (Steunou et al., 2020a). Similarly, in the cadR ${ }^{-}$ mutant, CopI is also more induced compared to the wild-type

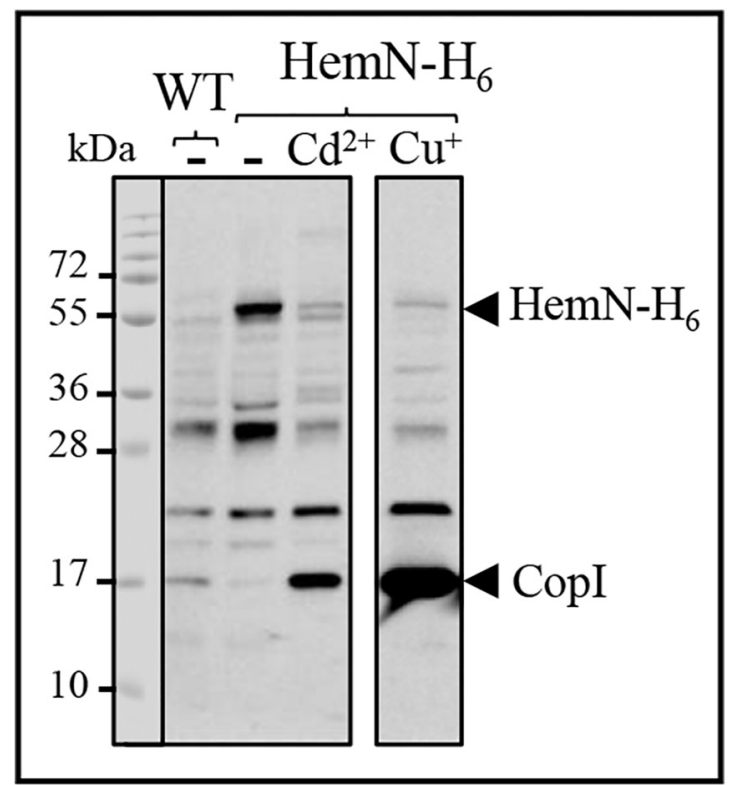

FIGURE 7 | Expression level of $\mathrm{HemN}^{-\mathrm{H}_{6}}$ in $R$. gelatinosus WT and $\mathrm{HemN}-\mathrm{H}_{6}$ strain in malate medium (-) or challenged with $1000 \mu \mathrm{M} \mathrm{CdCl}_{2}\left(\mathrm{Cd}^{2+}\right)$ or $500 \mu \mathrm{M} \mathrm{CuSO}_{4}\left(\mathrm{Cu}^{+}\right)$. Cells were grown overnight (18 h) under photosynthetic condition. Soluble protein fractions $(20 \mu \mathrm{g})$ were separated on a 15\% Tris-glycine SDS-PAGE. Proteins were visualized after Western blotting using the HRP-HisProbe.

strain. Once again, this difference in expression could arise from the accumulation of $\mathrm{Cd}^{2+}$ in the cytoplasm of $\mathrm{cadR}^{-}$cells devoid of the $\mathrm{Cd}^{2+}$-efflux ATPase. The data suggested that either CopR can interact with $\mathrm{Cd}^{2+}$ to induce CopI or that other regulators can induce CopI expression in the $c a d R^{-}$strain.

Given the induction of CopI, the periplasmic copper tolerance protein, by excess $\mathrm{Cd}^{2+}$ (Figures 2, 3), we wondered whether CopI was required for $\mathrm{Cd}^{2+}$ resistance. The $\Delta$ copI mutant was sensitive only to high $\mathrm{Cd}^{2+}$ concentration. However, the presence of CadA in the $\triangle c o p I$ mutant made the conclusion elusive. To confirm its requirement for $\mathrm{Cd}^{2+}$ tolerance, we question whether inactivation of $\operatorname{copI}$ in the $\triangle$ cadA background could give rise to a higher $\mathrm{Cd}^{2+}$ sensitivity in such a strain. The double mutant $\Delta c a d A \_\Delta c o p I$ was constructed and its tolerance towards $\mathrm{Cd}^{2+}$ was compared to that of $\Delta c a d A$ strain on plates (Figure 8A) and liquid (Figure 8B and Supplementary Figure S5) under photosynthesis conditions. The double mutant $\Delta c a d A_{-} \Delta c o p I$ was indeed more sensitive to $\mathrm{Cd}^{2+}$ than the $\Delta$ cadA mutant when exposed to $150 \mu \mathrm{M}$ and $200 \mu \mathrm{M} \mathrm{CdCl}_{2}$ on plates, and to $75 \mu \mathrm{M} \mathrm{CdCl} 2$ in liquid, thus confirming that CopI is somehow involved in $\mathrm{Cd}^{2+}$ tolerance. The underlying mechanism is not yet known, however, CopI was shown to be periplasmic and displays conserved His and Met residues that could interact with cations (Durand et al., 2015). It is then tempting to speculate that CopI may handle $\mathrm{Cd}^{2+}$ within the periplasm. 


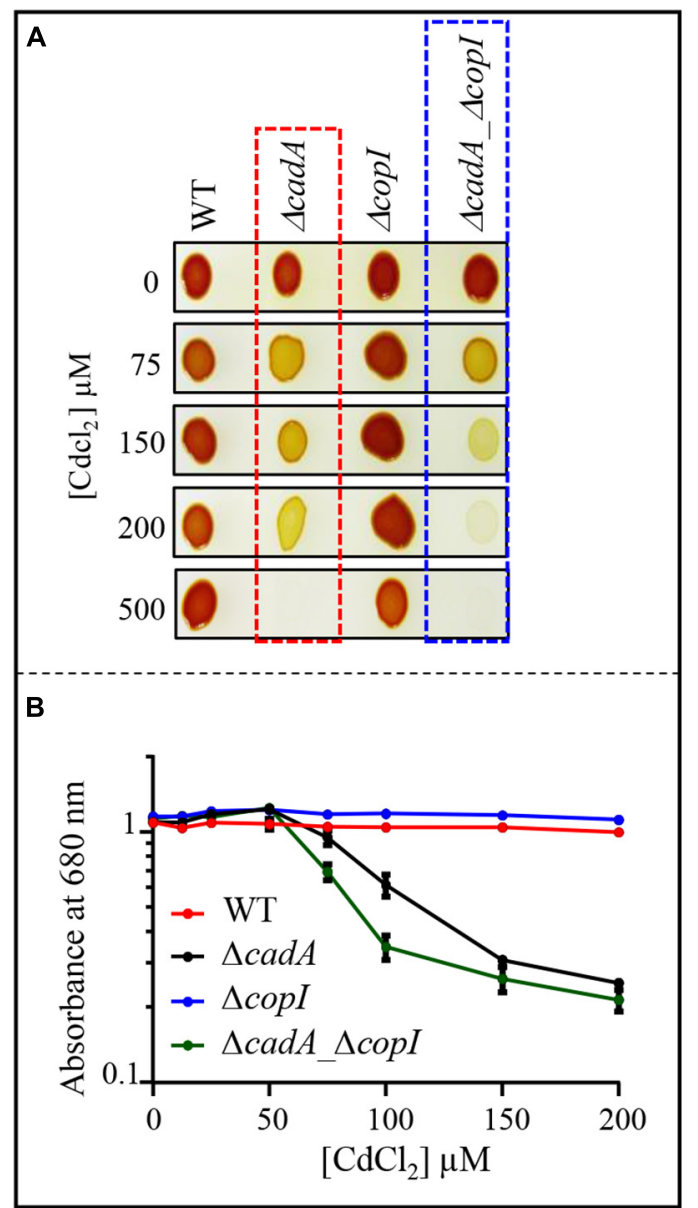

FIGURE 8 | (A) Growth phenotype of the wild-type (WT), $\Delta$ cadA, $\Delta$ copl, and $\Delta$ cadA- $\Delta$ cop/ mutants in the presence of increasing $\mathrm{CdCl}_{2}$ concentrations on solid plates. Cells were grown by photosynthesis for $48 \mathrm{~h}$ at $30^{\circ} \mathrm{C}$ prior to photography. (B) Growth inhibition of the wild-type, $\Delta c a d A, \Delta c o p l$, and $\Delta$ cadA_ $\Delta$ copl mutants challenged with increasing $\mathrm{CdCl}_{2}$ concentration. Cells were grown in liquid under photosynthetic condition for $21 \mathrm{~h}$ at $30^{\circ} \mathrm{C}$ before $\mathrm{OD}_{680 \mathrm{~nm}}$ measurement. The error bars represent the standard deviation of the mean of 3 independent experiments.

\section{The $\mathrm{Cu}^{+}$-ATPase CopA Is Induced by $\mathrm{Cd}^{2+}$ and $\mathrm{Cu}^{+}$Enhances Cadmium Tolerance in the $\Delta c a d A$ Strain}

Induction of CopI expression in response to both $\mathrm{Cu}^{+}$and $\mathrm{Cd}^{2+}$, suggests a cross-tolerance towards these metals and raised the question on the ability of $\mathrm{Cu}^{+}$to enhance the resistance of $\triangle c a d A$ strain to increasing concentration of $\mathrm{Cd}^{2+}$. To answer this question, we assessed the growth inhibition of $\triangle$ cadA strain grown under photosynthesis condition in $\mathrm{Cd}^{2+}$ containing medium supplemented or not with $200 \mu \mathrm{M} \mathrm{CuSO}$. No significant difference in growth of the wild-type strain was observed between the two conditions, both on solid (Figure 9A) and liquid media (Figure 9B). Interestingly, for the $\triangle c a d A$ strain, the addition of $\mathrm{CuSO}_{4}$ in the medium significantly improved growth of the mutant, suggesting that, $\mathrm{Cu}^{+}$alleviates $\mathrm{Cd}^{2+}$ stress.

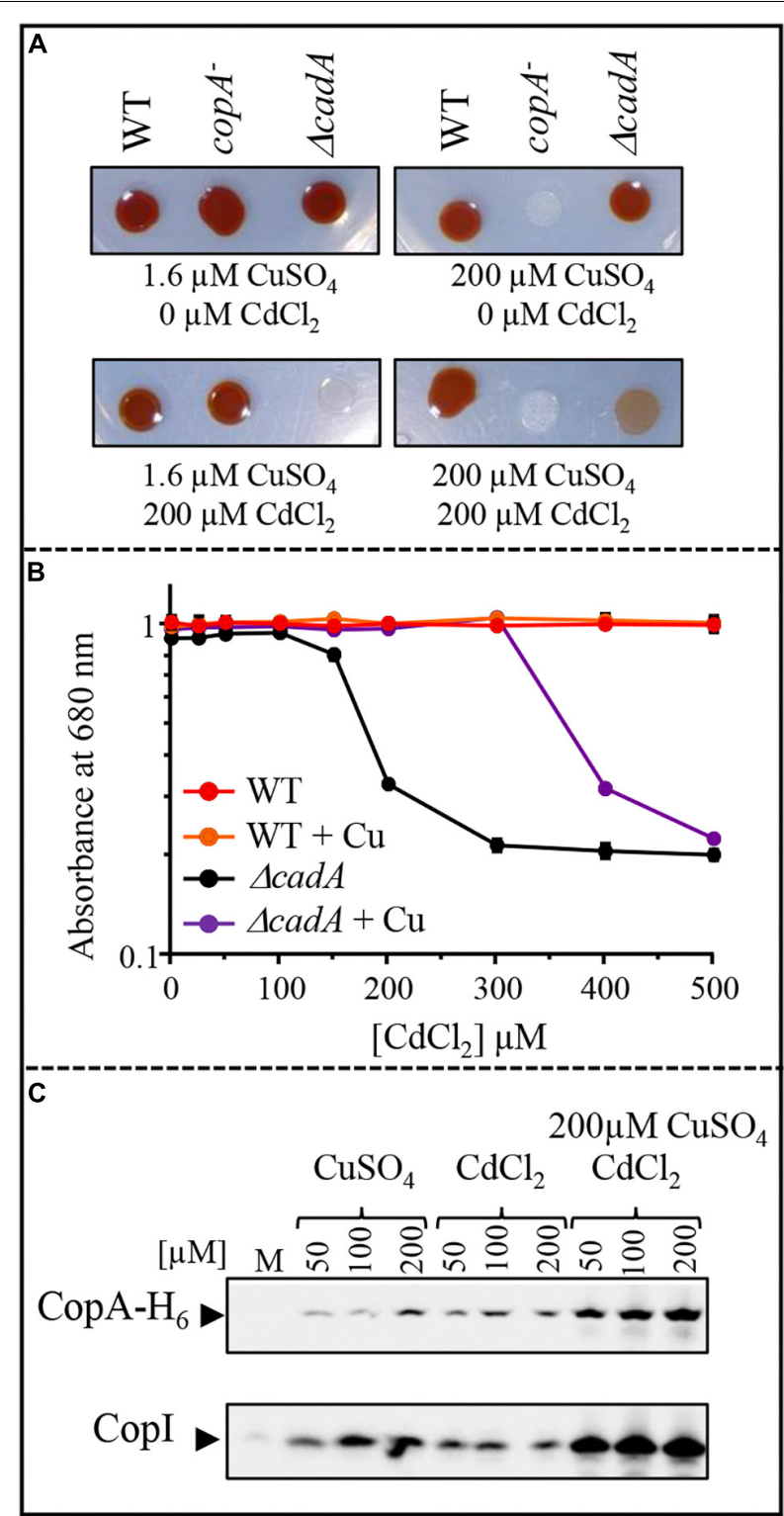

FIGURE 9 | Effect of $\mathrm{CuSO}_{4}$ on growth in the presence of increasing concentration of $\mathrm{CdCl}_{2}$. (A) Growth phenotype of the wild-type (WT), $\Delta$ cadA and copA- strains in presence of increasing $\mathrm{CdCl}_{2}$ concentration with or without addition of $200 \mu \mathrm{M} \mathrm{CuSO}_{4}$ on solid plates. (B) Growth inhibition of the wild-type and $\triangle$ cadA mutant challenged with increasing $\mathrm{CdCl}_{2}$ concentration in the medium supplemented or not with $200 \mu \mathrm{M} \mathrm{CuSO}_{4}$. Cells were grown under photosynthetic condition for $18 \mathrm{~h}$ at $30^{\circ} \mathrm{C}$ before $\mathrm{OD}_{680 \mathrm{~nm}}$ measurement. The error bars represent the standard deviation of the mean of 3 independent experiments. (C) Expression level of CopA- $\mathrm{H}_{6}$ and Copl in $R$. gelatinosus $\triangle$ cadA-copA- $H_{6}$ mutant challenged with increasing concentration of $\mathrm{CuSO}_{4}, \mathrm{CdCl}_{2}$, or $\mathrm{CdCl}_{2}+\mathrm{CuSO}_{4}$. Cells were grown in the malate $(\mathrm{M})$ medium supplemented or not with metals, under photosynthetic condition. Total protein extract from the same amount of cells $\left(\mathrm{OD}_{680 \mathrm{~nm}}=0.1\right)$ were separated on a $15 \%$ tris-glycine SDS-PAGE. Proteins were visualized after Western blotting using the HRP-HisProbe.

Similar results were obtained under aerobic respiration (Supplementary Figure S6). 
Given that exposure to $\mathrm{Cu}^{+}$caused an induction of the CopA-CopI system (Azzouzi et al., 2013; Durand et al., 2015), the enhanced growth observed in $\Delta c a d A$ strain could be the result of an up-regulation of CopA and CopI expression by the simultaneous effect of $\mathrm{Cu}^{+}$and $\mathrm{Cd}^{2+}$ in the cell. To check the expression of CopA in response to both $\mathrm{Cd}^{2+}$ and $\mathrm{Cu}^{+}$in the $\triangle c a d A$ background, we constructed a $\triangle c a d A$ strain bearing a $\operatorname{cop} A$ histidine fusion gene $\left(\operatorname{cop} A-H_{6}\right)$ integrated to the $\operatorname{cop} A$ locus on the chromosome of $R$. gelatinosus to allow detection on Western blot. In this $\triangle$ cadA_copA- $H_{6}$ strain, the transcription of $\operatorname{cop} A-H_{6}$ is under the control of its endogenous $\mathrm{Cu}^{+}$-regulated promoter. The strain was grown under photosynthesis condition with increasing $\mathrm{CuSO}_{4}$ and/or $\mathrm{CdCl}_{2}$ concentrations and whole cell extracts were probed for the presence of CopA- $\mathrm{H}_{6}$. The presence of both metals resulted in a significant increase in the amount of CopA- $\mathrm{H}_{6}$ and CopI within the cells (Figure 8C). These findings clearly showed that as for CopI and CadA, $\mathrm{Cd}^{2+}$ induced the $\mathrm{Cu}^{+}$-ATPase CopA. Although transport of $\mathrm{Cd}^{2+}$ by CopA is not yet shown, the data suggest a role of CopA and CopI in $\mathrm{Cd}^{2+}$ tolerance. In agreement with this assumption, we assessed growth on $\mathrm{Cd}^{2+}$ alone or on $\mathrm{Cd}^{2+}$ and $\mathrm{Cu}^{+}$of a $\triangle$ cadA_copA $A^{-}$ double mutant devoid of both CadA and CopA ATPases. In contrast to $\triangle c a d A$ single mutant, no difference in growth was observed between the two conditions for the double mutant (Supplementary Figure S7). Together with the involvement of $\mathrm{Cd}^{2+}$ in $\mathrm{Cu}^{+}$-homeostasis system induction, these new findings suggested a cross-talk and -tolerance between the $\mathrm{Cd}^{2+}$ and $\mathrm{Cu}^{+}$ efflux system in R. gelatinosus.

\section{DISCUSSION}

Heavy metal contamination represents a serious threat to the environment and all living organisms because of their acute toxicity. Understanding toxicity is an intricate issue because of the presence of efficient metal detoxification systems; however, the availability of strains defective in a metal homeostasis machinery allowed the identification of new metal targets and shed light on the toxicity mechanisms. Successful efforts have been made to understand the mechanisms by which bacteria respond and deal with single metal excess (Arguello et al., 2007; Barwinska-Sendra and Waldron, 2017; Capdevila et al., 2017; Chandrangsu et al., 2017). In the present study, the $\mathrm{Cd}^{2+}$-efflux ATPase defective mutant of $R$. gelatinosus provides a useful tool to identify targets of $\mathrm{Cd}^{2+}$ within the cells. Exposure of $\triangle c a d A$ to excess $\mathrm{Cd}^{2+}$ resulted in a decreased amount of the light harvesting and reaction center (LH-RC) photosynthetic complexes and a decreased amount of the respiratory complexes succinate dehydrogenase (SDH) and $c b b_{3}$ cytochrome $c$ oxidase. Both $c b b_{3}$ and SDH are hemoproteins, while the LH-RC complex assembly and activity are bacteriochlorophyll dependent. This decrease is concomitant to the decrease in heme and bacteriochlorophyll production. Moreover, noticeably, under microaerobic respiration and photosynthesis growth conditions, the $\Delta c a d A$ mutant extruded coproporphyrin III. These data showed that when challenged with excess $\mathrm{Cd}^{2+}$, the tetrapyrrole biosynthesis pathway was affected at the level of the anaerobic coproporphyrinogen III oxidase HemN. HemN is an [4Fe-4S] cluster-dependent enzyme, with a cluster coordinated only by three cysteines and the methionine group of $S$-adenosylmethionine. This cluster is located within the active site pocket that accommodates two SAM molecules and the coproporphyrinogen III (Layer et al., 2003, 2004). This pocket is likely solvent accessible, making the $[4 \mathrm{Fe}-4 \mathrm{~S}]$ cluster vulnerable to molecular oxygen but also very likely towards metal ions (Azzouzi et al., 2013; Djoko and McEwan, 2013). The $\mathrm{Cd}^{2+}$-related porphyrin phenotype was observed only under microaerobic respiration or photosynthesis conditions in which HemN is required for the tetrapyrrole biosynthesis pathway, but not under high aeration when the aerobic coproporphyrinogen III oxidase HemF performs the oxidation of coproporphyrinogen III (Breckau et al., 2003). We therefore suggest that $\mathrm{Cd}^{2+}$, like oxygen an $\mathrm{Cu}^{+}$, affects tetrapyrrole biosynthesis presumably at the level of the SAM and [4Fe-4S] containing HemN enzyme.

Under aerobic respiration condition, $\Delta c a d A$ growth is even more affected by $\mathrm{Cd}^{2+}$ than under photosynthesis condition, this might be related to the synergetic toxic effects of $\mathrm{Cd}^{2+}$ and oxygen. Yet, the $\mathrm{Cd}^{2+}$ targets remain to be identified in R. gelatinosus. Given that $\mathrm{Cd}^{2+}$ targets [4Fe-4S] clusters under microaerobic respiration and photosynthesis conditions, it is tempting to suggest that other oxygen sensitive [4Fe-4S] dehydratases may be poisoned by the simultaneous presence of oxygen and $\mathrm{Cd}^{2+}$, as shown in E. coli (Xu and Imlay, 2012) and in R. gelatinosus (Liotenberg et al., 2015).

In their environment, bacteria are exposed to a mixture of metals (Ye et al., 2017). This can cause interactions between metals, enhanced toxicity or on the contrary, generate crossresistance towards different metals. Interestingly, we identified CopI, known to be involved in $\mathrm{Cu}^{+}$tolerance (Durand et al., 2015), as also involved in $\mathrm{Cd}^{2+}$ tolerance since deletion of copI in $\triangle c a d A$ mutant resulted in an increased sensitivity to $\mathrm{Cd}^{2+}$. The mechanism by which CopI interferes with $\mathrm{Cd}^{2+}$ tolerance is unknown, however, since CopI interacts with $\mathrm{Cu}^{+}, \mathrm{Cd}^{2+}$ may also interact with the apo-CopI protein in the absence of $\mathrm{Cu}^{+}$. In $P$. aeruginosa, the $p c o A B$ genes are induced by $\mathrm{Cu}^{+}$ and encode periplasmic $\mathrm{Cu}^{+}$binding proteins. The $p c o A B$ genes are also suggested to be involved in $\mathrm{Zn}^{2+}$ and probably $\mathrm{Cd}^{2+}$ tolerance since the $p c o A B$ mutants are more sensitive to $\mathrm{Zn}^{2+}$ (Teitzel et al., 2006).

Interaction of $\mathrm{Cd}^{2+}$ with cupro-protein, albeit with low affinity, have been reported in the case of the $\mathrm{Cu}^{+}$chaperone CopZ involved in copper efflux in Bacillus (B.) subtilis and other bacteria (Kihlken et al., 2008). As for copI, the copZ deletion in $B$. subtilis resulted in an increased sensitivity to both $\mathrm{Cu}^{+}$ and $\mathrm{Cd}^{2+}$ and expression of the $\operatorname{cop} Z A$ operon was induced in response to elevated concentrations of both metals (Moore et al., 2005; Steunou et al., 2020a). Similarly, in Pseudomonas (P.) aeruginosa $\mathrm{Cu}^{+}$induces the activation of the $c z c C B A$ operon involved in the efflux of $\mathrm{Zn}^{2+}, \mathrm{Cd}^{2+}$, and $\mathrm{Co}^{2+}$ (Caille et al., 2007). In our study, $\mathrm{Cd}^{2+}$ is shown to induce the $\mathrm{Cd}^{2+}$-efflux ATPase CadA and the $\mathrm{Cu}^{+}$-efflux ATPase CopA in R. gelatinosus. In addition, $\mathrm{Cu}^{+}$improves $\mathrm{Cd}^{2+}$ tolerance in the CadA deficient mutant, suggesting that CopA and CopI are somehow involved in 
$\mathrm{Cd}^{2+}$ detoxification. The involvement of CopA in $\mathrm{Cd}^{2+}$ or $\mathrm{Zn}^{2+}$ efflux has never been demonstrated and seems very unlikely. Nevertheless, the cross-talk between $\mathrm{Cu}^{+}$and or $\mathrm{Zn}^{2+} / \mathrm{Cd}^{2+}$ efflux systems, at least at the expression level, was previously reported in other bacteria. In P. aeruginosa, both PA3920 gene encoding CopA and PA3690 encoding ZntA/CadA homologue are induced by $\mathrm{Cu}^{+}$stress (Teitzel et al., 2006). We should stress out that in this study, $P$. aeruginosa wild type cells were exposed to a very high concentration of $\mathrm{CuSO}_{4}(10 \mathrm{mM})$. In a more recent study, Arguello's group used RNA-Seq to characterize the response of $P$. aeruginosa to $0.5 \mathrm{mM} \mathrm{CuSO}_{4}$ to avoid pleiotropic effects that could be related to elevated concentration of $\mathrm{CuSO}_{4}$ (Quintana et al., 2017). PA3690 (ZntA/CadA) was not induced in the wild type, nevertheless, in the $\triangle c u e R$ and $\triangle c o p R$ mutant, a 3.6 and 2 fold change in the expression of PA3690 was observed in these mutants (Quintana et al., 2017). Likewise, in the filamentous cyanobacterium Oscillatoria brevis, expression of the ATPase Bxal is also induced by both $\mathrm{Cd}^{2+}$ and $\mathrm{Cu}^{+}$cations (Liu et al., 2004). Cross-tolerance towards $\mathrm{Cu}^{+}$and $\mathrm{Zn}^{2+}$ or $\mathrm{Cd}^{2+}$ involving these ATPases, was not investigated in these bacteria.

Although the mechanism and physiological significance behind $\mathrm{Cu}^{+} / \mathrm{Cd}^{2+}$ growth improvement reported in this work remain unclear and require further investigation, the cross-talk and cross-tolerance reported in all these studies emphasize on the importance of interactions and toxicity that could arise from metal mixtures and show that research should further consider mixtures effects.

Metal ability to undergo redox reactions is important for its function as protein cofactor but also for its intrinsic toxicity. $\mathrm{Cd}^{2+}$ is not redox active and cannot directly trigger ROS formation, yet, it is very toxic. It was suggested that $\mathrm{Cd}^{2+}$ could indirectly promote ROS production by displacing and releasing redox active ions such as iron or copper from proteins

\section{REFERENCES}

Arguello, J. M., Eren, E., and Gonzalez-Guerrero, M. (2007). The structure and function of heavy metal transport P1B-ATPases. Biometals 20, 233-248. doi: 10.1007/s10534-006-9055-6

Azzouzi, A., Steunou, A. S., Durand, A., Khalfaoui-Hassani, B., Bourbon, M. L., Astier, C., et al. (2013). Coproporphyrin III excretion identifies the anaerobic coproporphyrinogen III oxidase $\mathrm{HemN}$ as a copper target in the $\mathrm{Cu}^{+}$-ATPase mutant copA $A^{-}$of Rubrivivax gelatinosus. Mol. Microbiol. 88, 339-351. doi: 10.1111/mmi. 12188

Baekgaard, L., Mikkelsen, M. D., Sorensen, D. M., Hegelund, J. N., Persson, D. P., Mills, R. F., et al. (2010). A combined zinc/cadmium sensor and zinc/cadmium export regulator in a heavy metal pump. J. Biol. Chem. 285, 31243-31252. doi: $10.1074 /$ jbc.m110.111260

Barwinska-Sendra, A., and Waldron, K. J. (2017). The Role of Intermetal Competition and Mis-Metalation in Metal Toxicity. Adv. Microb. Physiol. 70, 315-379. doi: 10.1016/bs.ampbs.2017.01.003

Breckau, D., Mahlitz, E., Sauerwald, A., Layer, G., and Jahn, D. (2003). Oxygen-dependent coproporphyrinogen III oxidase (HemF) from Escherichia coli is stimulated by manganese. J. Biol. Chem. 278, 46625-46631. doi: 10.1074/jbc.m308553200

Caille, O., Rossier, C., and Perron, K. (2007). A copper-activated two-component system interacts with zinc and imipenem resistance in Pseudomonas aeruginosa. J. Bacteriol. 189, 4561-4568. doi: 10.1128/jb.00095-07
(Xu and Imlay, 2012; Barwinska-Sendra and Waldron, 2017). Induction of SodB expression in the $\Delta c a d A$ strain suggests an increase in ROS production or a dysregulation of iron homeostasis since SodB is known to be regulated by Fur regulator in bacteria. Together with the degradation of solvent exposed [4Fe-4S] cluster from key metabolic enzymes, iron homeostasis dysregulation and ROS should be considered to account for the $\mathrm{Cd}^{2+}$ toxicity in the $\Delta$ cadA strain (Steunou et al., 2020b).

\section{DATA AVAILABILITY STATEMENT}

The raw data supporting the conclusions of this article will be made available by the authors, without undue reservation, to any qualified researcher.

\section{AUTHOR CONTRIBUTIONS}

AS, AD, MB, SL, and SO designed the research. AS, AD, M-LB, $\mathrm{RT}$, and SO performed the research. AS, AD, MB, SL, M-LB, and $\mathrm{SO}$ analyzed the data. AS and SO wrote the manuscript.

\section{ACKNOWLEDGMENTS}

We gratefully acknowledge the support of the CNRS and the Microbiology department of I2BC.

\section{SUPPLEMENTARY MATERIAL}

The Supplementary Material for this article can be found online at: https://www.frontiersin.org/articles/10.3389/fmicb. 2020.00893/full\#supplementary-material

Capdevila, D. A., Edmonds, K. A., and Giedroc, D. P. (2017). Metallochaperones and metalloregulation in bacteria. Essays Biochem. 61, 177-200. doi: 10.1042/ ebc20160076

Chandrangsu, P., Rensing, C., and Helmann, J. D. (2017). Metal homeostasis and resistance in bacteria. Nat. Rev. Microbiol. 15, 338-350. doi: 10.1038/nrmicro.2017.15

Djoko, K. Y., and McEwan, A. G. (2013). Antimicrobial action of copper is amplified via inhibition of heme biosynthesis. ACS Chem. Biol. 8, 2217-2223. doi: $10.1021 / \mathrm{cb} 4002443$

Durand, A., Azzouzi, A., Bourbon, M. L., Steunou, A. S., Liotenberg, S., Maeshima, A., et al. (2015). c-type cytochrome assembly is a key target of copper toxicity within the bacterial periplasm. mBio 6, e01007-e01015.

Gonzalez-Guerrero, M., Raimunda, D., Cheng, X., and Arguello, J. M. (2010). Distinct functional roles of homologous $\mathrm{Cu}+$ efflux ATPases in Pseudomonas aeruginosa. Mol. Microbiol. 78, 1246-1258. doi: 10.1111/j.1365-2958.2010. 07402.x

Haan, C., and Behrmann, I. (2007). A cost effective non-commercial ECL-solution for Western blot detections yielding strong signals and low background. J. Immunol. Methods 318, 11-19. doi: 10.1016/j.jim.2006.07.027

Khalfaoui Hassani, B., Steunou, A. S., Liotenberg, S., Reiss-Husson, F., Astier, C., and Ouchane, S. (2010). Adaptation to oxygen: Role of terminal oxidases in photosynthesis initiation in the purple photosynthetic bacterium. Rubrivivax gelatinosus. J. Biol. Chem. 285, 19891-19899. doi: 10.1074/jbc.m109. 086066 
Kihlken, M. A., Singleton, C., and Le Brun, N. E. (2008). Distinct characteristics of $\mathrm{Ag}+$ and $\mathrm{Cd} 2+$ binding to CopZ from Bacillus subtilis. J. Biol. Inorg. Chem. 13, 1011-1023. doi: 10.1007/s00775-008-0388-1

Layer, G., Heinz, D. W., Jahn, D., and Schubert, W. D. (2004). Structure and function of radical SAM enzymes. Curr. Opin. Chem. Biol. 8, 468-476. doi: 10.1016/j.cbpa.2004.08.001

Layer, G., Moser, J., Heinz, D. W., Jahn, D., and Schubert, W. D. (2003). Crystal structure of coproporphyrinogen III oxidase reveals cofactor geometry of Radical SAM enzymes. EMBO J. 22, 6214-6224. doi: 10.1093/emboj/cdg598

Legatzki, A., Grass, G., Anton, A., Rensing, C., and Nies, D. H. (2003). Interplay of the Czc system and two P-type ATPases in conferring metal resistance to Ralstonia metallidurans. J. Bacteriol. 185, 4354-4361. doi: 10.1128/jb.185.15. 4354-4361.2003

Li, J., Ren, X., Fan, B., Huang, Z., Wang, W., Zhou, H., et al. (2019). Zinc Toxicity and Iron-Sulfur Cluster Biogenesis in Escherichia coli. Appl. Environ. Microbiol. 85, e1967-e1918.

Liotenberg, A., Steunou, A. S., Durand, A., Bourbon, M. L., Bollivar, D. W., Hansson, M., et al. (2015). Oxygen-dependent copper toxicity: targets in the chlorophyll biosynthesis pathway identified in the copper efflux ATPase CopA deficient mutant. Environ. Microbiol, 17, 1963-1976. doi: 10.1111/1462-2920. 12733

Liu, T., Nakashima, S., Hirose, K., Shibasaka, M., Katsuhara, M., Ezaki, B., et al. (2004). A novel cyanobacterial SmtB/ArsR family repressor regulates the expression of a CPx-ATPase and a metallothionein in response to both $\mathrm{Cu}(\mathrm{I}) / \mathrm{Ag}(\mathrm{I})$ and $\mathrm{Zn}(\mathrm{II}) / \mathrm{Cd}(\mathrm{II})$. J. Biol. Chem. 279, 17810-17818. doi: 10.1074/ jbc.m310560200

Lu, M., Li, Z., Liang, J., Wei, Y., Rensing, C., and Wei, G. (2016). Zinc Resistance Mechanisms of P1B-type ATPases in Sinorhizobium meliloti CCNWSX0020. Sci. Rep. 6:29355.

Macomber, L., and Imlay, J. A. (2009). The iron-sulfur clusters of dehydratases are primary intracellular targets of copper toxicity. Proc. Natl. Acad. Sci. U.S.A. 106, 8344-8349. doi: $10.1073 /$ pnas.0812808106

Macomber, L., Rensing, C., and Imlay, J. A. (2007). Intracellular copper does not catalyze the formation of oxidative DNA damage in Escherichia coli. J. Bacteriol. 189, 1616-1626. doi: 10.1128/jb.01357-06

Mana-Capelli, S., Mandal, A. K., and Arguello, J. M. (2003). Archaeoglobus fulgidus $\mathrm{CopB}$ is a thermophilic $\mathrm{Cu} 2+-\mathrm{ATPase}$ functional role of its histidine-rich-N-terminal metal binding domain. J. Biol. Chem. 278, 40534-40541. doi: 10.1074/jbc.m306907200

Moore, C. M., Gaballa, A., Hui, M., Ye, R. W., and Helmann, J. D. (2005). Genetic and physiological responses of Bacillus subtilis to metal ion stress. Mol. Microbiol. 57, 27-40. doi: 10.1111/j.1365-2958.2005.04642.x

Nunes, I., Jacquiod, S., Brejnrod, A., Holm, P. E., Johansen, A., Brandt, K. K., et al. (2016). Coping with copper: legacy effect of copper on potential activity of soil bacteria following a century of exposure. FEMS Microbiol. Ecol. 92:fiw175. doi: 10.1093/femsec/fiw175

Ouchane, S., Picaud, M., Reiss-Husson, F., Vernotte, C., and Astier, C. (1996). Development of gene transfer methods for Rubrivivax gelatinosus S1: construction, characterization and complementation of a puf operon deletion strain. Mol. Gen. Genet. 252, 379-385. doi: 10.1007/bf02173002

Quintana, J., Novoa-Aponte, L., and Arguello, J. M. (2017). Copper homeostasis networks in the bacterium Pseudomonas aeruginosa. J. Biol. Chem. 292, 1569115704. doi: 10.1074/jbc.m117.804492

Rensing, C., Sun, Y., Mitra, B., and Rosen, B. P. (1998). Pb(II)-translocating P-type ATPases. J. Biol. Chem. 273, 32614-32617. doi: 10.1074/jbc.273.49.32614

Roy, P., Bauman, M. A., Almutairi, H. H., Jayawardhana, W. G., Johnson, N. M., and Torelli, A. T. (2018). Comparison of the response of bacterial IscU and
SufU to $\mathrm{Zn}(2+)$ and select transition-metal ions. ACS Chem. Biol. 13, 591-599. doi: 10.1021/acschembio.7b00442

Sakpirom, J., Kantachote, D., Nunkaew, T., and Khan, E. (2017). Characterizations of purple non-sulfur bacteria isolated from paddy fields, and identification of strains with potential for plant growth-promotion, greenhouse gas mitigation and heavy metal bioremediation. Res. Microbiol. 168, 266-275. doi: 10.1016/j. resmic.2016.12.001 doi: 10.1016/j.resmic.2016.12.001

Sambrook, J., Fritsch, E. F., and Maniatis, T. (1989). Molecular Cloning, A Laboratory Manual, 2nd Edn. New York, NY: Cold Spring Harbor.

Singh, V. K., Xiong, A., Usgaard, T. R., Chakrabarti, S., Deora, R., Misra, T. K., et al. (1999). ZntR is an autoregulatory protein and negatively regulates the chromosomal zinc resistance operon znt of Staphylococcus aureus. Mol. Microbiol. 33, 200-207. doi: 10.1046/j.1365-2958.1999.01466.x

Solovieva, I. M., and Entian, K. D. (2004). Metalloregulation in Bacillus subtilis: the copZ chromosomal gene is involved in cadmium resistance. FEMS Microbiol. Lett. 236, 115-122. doi: 10.1111/j.1574-6968.2004.tb09636.x

Steunou, A. S., Babot, M., Bourbon, M. L., Tambosi, R., Durand, A., Liotenberg, S., et al. (1999). Additive effects of metal excess and superoxide, a highly toxic mixture in bacteria. Microb. Biotechnol. (In press)

Steunou, A. S., Babot, M., Bourbon, M. L., Tambosi, R., Durand, A., Liotenberg, S., et al. (2020a). Additive effects of metal excess and superoxide, a highly toxic mixture in bacteria. Microb. Biotechnol. (in press).

Steunou, A. S., Bourbon, M. L., Babot, M, Durand, A., Liotenberg, S., Yamaichi, Y., et al. (2020b). Increasing the copper sensitivity of microorganisms by restricting iron supply, a strategy for bio-management practices. Microb. Biotechnol. (in press).

Tan, G., Yang, J., Li, T., Zhao, J., Sun, S., Li, X., et al. (2017). Anaerobic copper toxicity and iron-sulfur cluster biogenesis in Escherichia coli. Appl. Environ. Microbiol. 83:e00867-17.

Teitzel, G. M., Geddie, A., De Long, S. K., Kirisits, M. J., Whiteley, M., and Parsek, M. R. (2006). Survival and growth in the presence of elevated copper: transcriptional profiling of copper-stressed Pseudomonas aeruginosa. J. Bacteriol. 188, 7242-7256. doi: 10.1128/jb.00837-06

von Rozycki, T., and Nies, D. H. (2009). Cupriavidus metallidurans: evolution of a metal-resistant bacterium. Antonie Van Leeuwenhoek 96, 115-139. doi: 10.1007/s10482-008-9284-5

Wittig, I., Karas, M., and Schagger, H. (2007). High resolution clear native electrophoresis for in-gel functional assays and fluorescence studies of membrane protein complexes. Mol. Cell Proteomics 6, 1215-1225. doi: 10.1074/ mcp.m700076-mcp200

Xu, F. F., and Imlay, J. A. (2012). Silver(I), mercury(II), cadmium(II), and zinc(II) target exposed enzymic iron-sulfur clusters when they toxify Escherichia coli. Appl. Environ. Microbiol. 78, 3614-3621. doi: 10.1128/aem.07368-11

Ye, J., Rensing, C., Su, J., and Zhu, Y. G. (2017). From chemical mixtures to antibiotic resistance. J. Environ. Sci. 62, 138-144. doi: 10.1016/j.jes.2017.09.003

Conflict of Interest: The authors declare that the research was conducted in the absence of any commercial or financial relationships that could be construed as a potential conflict of interest.

Copyright (c) 2020 Steunou, Durand, Bourbon, Babot, Tambosi, Liotenberg and Ouchane. This is an open-access article distributed under the terms of the Creative Commons Attribution License (CC BY). The use, distribution or reproduction in other forums is permitted, provided the original author(s) and the copyright owner(s) are credited and that the original publication in this journal is cited, in accordance with accepted academic practice. No use, distribution or reproduction is permitted which does not comply with these terms. 